\title{
The Impact of a Play-Based Training Program on Reducing the Negative Effects of Students Abuse and Improving Their Self-Esteem
}

\author{
Hisham Ali Aldmour ${ }^{1}$ \\ ${ }^{1}$ Karak University College, Al-Balqa Applied University, Jordan \\ Correspondence: Hisham Ali Aldmour, Karak University College, Al-Balqa Applied University, Jordan.
}

Received: December 12, 2018

Accepted: January 21, 2019

Online Published: July 29, 2019

doi:10.5539/ies.v12n8p94

URL: https://doi.org/10.5539/ies.v12n8p94

\begin{abstract}
The aim of this study was to investigate the effect of a play-based program on reducing the effects of student's abuse and to improving their self-esteem. To achieve this goal, a sample was selected and composed of 60 male and female abused students. They were divided into two groups: control group and experimental group which both consisted of 30 students. The experimental group was divided into two groups: the first consisted of 15 male students, while the second consisted of 15 female students. The measure of exposure to abuse and the self-assessment scale were applied as an anterior and posterior test of both experimental and control groups. The experimental group was only exposed to training through the training program.

After completing the data collection, the means and standard deviations of the performance of the experimental and control groups were calculated on the study scales. The multivariate variance analysis was also conducted to identify the impact of the training program on gender. The results of this study showed statistically significant differences at the mean level $(\alpha \leq 0.05)$ between the performance mean of experimental and control groups. These differences were in favor of the experimental group that improved their level of self-esteem and decreased the level of exposure to abuse. The results also showed that there were no statistically significant differences at the level of significance $(\alpha \leq 0.05)$ between the female and male performance means.
\end{abstract}

Keywords: play-based training, self-esteem, students abuse, negative effects

\section{Introduction}

The phenomenon of child abuse is not the result of contemporary age, but it is old in many human societies, where it attracts Arab and international scholar attention. This is evident through international conventions and legislations, research and studies that have spotted this issue, and discussed forms of abuse (Physical, Emotional and Negligence) with varying degrees. This led educators, academics, psychologists and social workers to seek laws and legislation that protect the children from multiple forms of violence.

This is clear from the World Health Organization report, which noted that violence and child abuse cost countries huge losses. Statistics indicate that injuries caused by violence and child abuse cost at least $4 \%$ of gross domestic product (GDP), in addition to the bitter physical and psycho-emotional suffering of these children. The report issued at the end of a four-day conference on combating violence in Vienna in 1991, which stated that about 1.6 million of people die every year from injuries caused by violence, mostly children and women, and other millions suffer from different psycho-emotional and physical injuries (Report of the Secretary-General of the United Nations, 2006).

Maltin (2001) suggests that the residues of the aggressive approach, that lacks tolerance and compassion, are still stuck in the minds of some individuals and their behavior in dealing with social attitudes. The problem of violence is a new- old problem that has always settled in our human arena to threaten our human security and progress. Despite the tremendous developments in thought and humanitarian action that are appropriate to civilization and urbanization, we are still witnessing the prevalence of violence among human beings, especially against children. It is gruesome that man uses force to dominate others, especially by the head of the family.

Lussier and Leblanc (2005) point out the multiplicity of approaches in which types of abuse against children can be divided into:

1) In terms of those responsible: There is abuse by the child towards the child; where the child is sometimes the criminal and the victim, and many children are abused by the father or mother. 
2) In terms of the quality of the abuse: There is physical abuse, that includes beating the child, and often result in injuries that may lead to death, while there is emotional abuse through insulting, mocking or ridiculing the victim.

3) In terms of inclusiveness: violence or abuse is practiced collectively when a group is engaged in violence or abuse against children, as in some groups that practice violence and abuse against children for the purpose of education.

4) In terms of motivation to abuse: There are several motives for abuse, frustration and failure may be a motive for abuse against children, and deprivation may be a motive for abuse as a means of compensation, whether this deprivation is material, economic or emotional.

Through reviewing the abuse classifications and their dimensions, it can be said that there are four dimensions of abuse that researchers like Darwish, Esquivel, Howtz, and Alfonso (2002) focused on:

1) Physical Abuse:

Physical abuse is defined as acts by parents or one of them that are violent towards the child, leading to body injuries. Common manifestations of this type of abuse are burns, wounds, and scratches in different parts of the body. This abuse may be intentional, reaction to any negative or positive behavior of the child (Chalabi, 2003).

Some evidences suggest that many children die from physical abuse. Many newspapers and magazines display the news of the deaths of some children as a result of physical abuse by parents or relatives (Asala, 2004).

2) Negligence-based Abuse:

It can be said that this abuse involves a major and fundamental failure on the part of parents, who raise and educate their children, in providing their basic needs, which are necessary for their growth or development, whether intentionally or unintentionally by showing uncared of these needs (Taha, 2008)

Child negligence is one of the most devastating forms of abuse of a child's psycho-emotional and physical health, when parents or guardians do not give him enough attention and medical, physical, educational or emotional care. Negligence represents a large proportion of the manifestations of child abuse at the level of the world; where many studies indicate a large proportion of children suffer from deprivation, especially in the basic and psycho-emotional needs (Decker, 1995, p. 464).

3) Sexual Abuse:

Sexual abuse is one of the most serious types of abuse suffered by children within the family. It is dangerous for them to survive in the adolescence and puberty period, and its effect remains in their memory. It contributes directly to the destruction of his personality, and suffering many mental disorders and delinquencies of children and adolescents later (Taha, 2008).

Although sexual abuse is one of the most serious types of abuse, it is rarely considered in the values and standards of the conservative Muslim community, and it is not recognized by the children, although they occur frequently among the group of mentally handicapped children (Safi \& Qara, 2009).

Sexual abuse refers to the use of the child to satisfy the sexual desires of an adult or adolescent, exposing the child to any sexual activity or behavior, and often involves sexual harassment of the child through touch the sexual harasser, or contact with him. Other forms of sexual abuse of the child are sexual exploitation of children through sexual images and pornography (Muro \& Kotman, 1995).

4) Emotional Abuse:

It is difficult to identify the concept of emotional abuse compared to physical or sexual abuse, because the manifestations of emotional abuse are ambiguous, and there are no visible or clear signs to those people around the child. Emotional abuse is one of the most serious forms of abuse to which a child is subjected.

Emotional abuse generally takes a variety of forms, which can be summarized as follows:

1) Exploitation: This occurs through getting something from the child as a result of his vulnerability, such as sexual abuse of the child by adults (Abu Alia, 2000).

2) The child's lack of acceptance by his parents: This occurs through rejecting the child's demands and not meeting his basic needs, especially when the child suffers from mental disability or negligence of providing appropriate and comprehensive care to the child (Woolfolk, 2006).

3) Terrorism: This requires forcing the child to view adult abuse, such as sexual abuse, or the threat of child abuse by individuals to force him to perform a behavior (Vig \& Kaminer, 2002). 
4) The child is insulted and defamed. This is done by defrauding the child and looking at him with irony, avoiding talking to him, ignoring him and not interacting with him (Ratrout, 2000).

The importance of playing in the framework of mental health and psycho-emotional therapy, as a means to understand the child, study his/her behavior, identify problems and treatment, which help in the social development of the child, and satisfying his/her psycho-emotional needs (Zahran, 2001).

Scientists have found that playing satisfies a variety of purposes, most notably the therapeutic function, which means the use of play activity, in a planned way, to achieve changes in the child's behavior and personality development, making his/her life more happy and productive (Annunziata, 2003).

Play therapy is a therapeutic approach to help a child who has experienced emotional difficulties or trauma, and it is used effectively with children who have experienced family difficulties such as divorce, abuse and aggression (Shen \& Sink, 2002).

The family is not only the emotional medium that believes in the child's psycho-emotional openness and personal cleavage; it is a social medium in which a tremendous amount of relationships and actions interact. Through the family atmosphere, the child discovers the rules of communication with others, recognizes his freedom and limits, distinguishes between rights and duties, between permissions and prohibitions, and recognizes the spirit of competition and solidarity, and the nature of the values of his social class.

Thus, social adaptability is also generated by reconciling two opposing forces that may form the nucleus of conflict for man if they are not effectively dealt with; the first is the "Id" that seeks to satisfy the immediate needs and desires that are socially unacceptable; while the second force is represented by the "Super Ego" which tries to restrain the power of the "ego" through the values, ideals, and morals required by religion and society.

Here we find the role of the family in reconciling these conflicting forces, to create a balance of discussion and dialogue with children to understand their needs and requirements, so that children do not have to satisfy these needs abroad. This balance is the basis for all parenting, through which the final outcome of a child's behavior is generated.

This behavior, in which the social integration of the child is achieved, provides the child with a stable social environment that is balanced and conducive to the child's education and the love of others, and many values, traditions and attitudes of tolerance or intolerance (Chen \& $\mathrm{Li}, 2000)$.

\subsection{The Study Problem}

Child abuse is a serious global problem, with many negative effects, such as symptoms of depression, fear and addiction, where there is a relationship between childhood abuse and mental health disorders, such as anxiety disorders, confused thoughts, and suicidal behavior. The issue of child abuse has been a major concern in the past three decades due to the negative impact of this phenomenon, and the increasing incidence of child abuse in most societies (Safi \& Dabur, 2007).

Since the topic of child abuse is very important, this study aims at raising awareness of the problem of child abuse, establishing preventive and curative programs to reduce its prevalence, and shedding light methodologically on the most appropriate treatment interventions with children who have attended these programs, which may contribute to better planning and working with them, to help them reduce abuse and improve their self-esteem.

\subsection{Importance of the Study}

The importance of the current study is to identify the effectiveness of the play-based program in reducing the effects of abuse, improving the self-esteem of the students who attended them, as well as addressing the issue of abuse, which is a problem affecting the essence of society. Child abuse has negative psycho-emotional, physical and social impacts. The importance of the study stems from the fact that it is an attempt to develop self-esteem of these children.

\subsection{Objectives of the Study}

The present study aims to achieve the following objectives:

1) Develop a play-based program to reduce the impact of abuse and to improve the self-esteem of children who are evening.

2) Investigate the effectiveness of a playing-based program to reduce the effects of abuse in children.

3) Identify the effectiveness of a playing-based program to improve the self-esteem of children who are attending these programs. 


\subsection{Study Questions}

This study attempts to answer the following questions:

1) Are there statistically significant differences in the reduction of the effects of abuse, attributed to the play-based training program among experimental and control group members?

2) Are there statistically significant differences in level of self-esteem attributed to the play-based training program among experimental and control group members?

3) Are there statistically significant differences in the effects of abuse among members of the experimental and control group attributed to gender?

\subsection{Terminology of Study}

Child abuse is defined as "any act that intentionally harms the child, such as severe beating, strangulation, burning, or use of sharp objects, resulting in serious physical injury, sexual disorders, or severe mental injuries. For the purposes of this study, the degree to which the child will receive the scale of exposure to abuse consists of:

1) Physical abuse: It is defined as acts of violence directed at the child by one or both parents resulting in physical harm. For the purpose of the study procedures, it is the degree to which the mentally handicapped child is exposed to abuse on the scale of abuse.

2) Psycho-emotional abuse: It is an excessive and unreasonable parental requirement that imposes on the child expectations greater than his abilities, and is shown through the disregard for the child, or through failure to provide the child with sufficient love, care and guidance. For the purposes of this study, it is the degree to which the mentally handicapped child is exposed as defined by the measure of abuse.

3) Negligence Abuse: It is the failure of parents who are in the process of upbringing and education of their children, in providing the requirements of their children, essential and necessary for their growth, such as food, clothing and medicine intentionally or unintentionally by showing apathy to these needs. For the purposes of the study procedures, it is the degree to which the mentally disabled child is exposed as defined by the abuse measure.

4) Self-Esteem: It means the rule adopted by the individual for himself in many life situations, whether this provision positive or negative, through the degree obtained by the student on the scale of self-esteem.

5) The playing-based program: it is an integrated system of planned and organized experiences, including a series of time-programmed activities and actions that will be experienced by the students in the experimental group, to assist children who experience emotional difficulties or trauma, so that they can adapt to and reduce the impact of exposure to abuse (Shen \& Sink, 2002). Procedurally it is defined as the program to be prepared for this study.

\section{Previous Studies}

There have been numerous studies on the subject of abuse at the level of Arab or foreign studies. However, within the limits of the researchers' knowledge, there is a scarcity of studies conducted on the effectiveness of play therapy in reducing the negative effects of abuse, and improve self-esteem among abused children. The following are a number of these studies:

Ibrahim (1994) aimed to identify the effectiveness of a community-based counseling program based on psychodrama as a therapeutic approach, to reduce emotional disorders among a group of children with special needs between the ages of 6-9 years. The experimental group was trained on the therapeutic program prepared for this study. They showed that the overall counseling program was effective in reducing emotional disorders in the experimental group.

Hattar (1995) study aimed at identifying the impact of a therapeutic program, based on the therapeutic drama, on self-esteem among a sample of children, between the ages of 8-13 years of experimental and control children groups of SOS in Amman, Jordan. In this study, a treatment program was applied to experimental group members only, while self-assessment questionnaire was applied to both experimental and control groups. The results of the study showed significant differences in the favor of experimental group.

Bryce (2005) examined the effectiveness of psychodrama in reducing anxiety and improving self-concept in a sample of (6) female students aged 9-12 years, who have been sexually abused. After the application of the treatment program on the sample of the study, the results indicated improvement of the concept of self-efficacy, through the performance of the sample on the scale prepared by Pierce Hares, and showed a significant decrease in the level of anxiety in the sample study. 
Abdul Jawad and Khalil (1999) study aimed to identify the effectiveness of a program to reduce aggressive behavior, by using play among children with mental disabilities. The sample consisted of (60) female and male children, ranging from (9-11) years. After applying the program to the members of the experimental group only, and using the observation, the results of the study found that there were differences of statistical significance between the experimental and control groups, in terms of the level of aggressive behavior, in favor of the experimental group, which received the strategy of playing to reduce aggressive behavior.

Gill (2005) examined the impact of the play therapy program on improving self-esteem and coping skills, reducing anger and aggression, improving satisfaction, and reducing the post-traumatic stress symptoms (PTSD), in a sample of 9-year-old children who were sexually abused, The sample of the study was trained on releasing their stress through playing, playing the symbolic role in order to eliminate anxiety and control the crisis of the past. The study found an improvement in self-efficacy and compatibility skills, and in achieving the previous goals.

\section{Study Procedures}

\subsection{Study Participants}

The study population is composed of all abused students of the lower elementary stage in Karak governorate. The measure of exposure to abuse was established and applied to 168 students.

\subsection{The Study Sample}

After correcting the responses of the students on the scale of exposure to abuse, a sample of 60 female and male students was taken from the abused student's population. After then, it was divided randomly into two groups: experimental and control, each of which included 30 abused students. The experimental group was also divided into two groups; one consisted of 15 male and the other consisted of 15 female abused students the control group was subjected to anterior and posterior measure without any training. Table (1) shows the distribution of the study sample by group and gender.

Table 1. Distribution of study group members by gender

\begin{tabular}{lccc}
\hline Group & \multicolumn{2}{c}{ Gender } & Total \\
\hline \multirow{2}{*}{ Experimental } & Male & Female & \multirow{2}{*}{30} \\
& 15 & 15 & \\
\multirow{2}{*}{ Control } & Male & Female & \multirow{2}{*}{30} \\
& 16 & 14 & \\
\hline
\end{tabular}

\subsection{Study Tools}

\section{Self-Assessment Scale:}

The scale was designed to consist of (50) items divided into five dimensions: sense of safety (10 items), sense of identity(10 items), sense of belonging (10 items), sense of goal (10 items), and sense of efficacy (10 items).

1) Validity of the scale:

The following validity indicators were ascertained:

\section{1) Content Validity:}

The scale was submitted to seven reviewers of specialists, as well as one specialist in the field of language and grammar, to show the accuracy of the items in terms of language accuracy and clarity of meaning, and to indicate the extent to which the item belongs to the dimension in which it was placed. The researcher complied with the notes of reviewers where he adopted the items agreed upon by them and altered the other items as required, while the percentage of the agreement exceeded $80 \%$ or more.

\section{2) Structure Accuracy:}

The self-assessment scale was applied to an external sample of 30 students randomly selected. The validity of the construction was calculated by correlation coefficients of the items in the fields in which they were included. As shown in Table 2. 
Table 2. Correlation matrix between the dimensions of the self-assessment scale

\begin{tabular}{|c|c|c|c|c|c|}
\hline Scale Dimensions & Sense Safety & $\begin{array}{c}\text { Sense of } \\
\text { identity }\end{array}$ & Sense of belongings & $\begin{array}{c}\text { Sense of } \\
\text { Goal }\end{array}$ & Sense of Competency \\
\hline Sense Safety & ----- & 0.08 & $0.58 * *$ & 0.18 & $0.32 * *$ \\
\hline Sense of identity & -0.06 & ------ & $0.34 * *$ & $0.62 * *$ & $0.28^{*}$ \\
\hline Sense of belonging & 0.05 & $-0.40 * *$ & ---- & $0.55 * *$ & $0.16^{* *}$ \\
\hline Sense of Goal & 0.02 & 0.06 & 0.18 & ---- & $0.14^{*}$ \\
\hline Sense of competency & $0.21 *$ & $0.24 *$ & 0.02 & 0.08 & ---- \\
\hline
\end{tabular}

* All Correlations are significant at $\alpha \leq 0.01$.

The results of Table 2 show that Pearson correlation coefficients between the test dimensions are statistically significant at the mean level $<0.01$.

\section{3) Stability of the self-assessment scale:}

It was confirmed that the scale was stable in two ways: the first using the Alpha-Cronbach formula, and the second was the mid-range split stability of each dimension of the scale separately, and for the total number of items, as shown in Table 3

Table 3. The values of stability coefficients according to the Alpha-Cronbach equation and the mid-range split of the various dimensions of the self-perceived efficiency scale

\begin{tabular}{lcc}
\hline Dimension & CronBach Alpha Stability Coefficient & \multirow{2}{*}{ mid-range split stability coefficient } \\
\cline { 1 - 2 } Sample N=30 & Sample N=30 & 0.84 \\
\cline { 1 - 2 } Sense of Safety & 0.81 & 0.83 \\
Sense. of identity & 0.82 & 0.85 \\
Sense of belonging & 0.86 & 0.79 \\
Sense.of Goal & 0.84 & 0.83 \\
Sense of Efficacy & 0.82 & \\
\hline
\end{tabular}

The results of the previous table indicate that the stability coefficients in the Cronbach Alpha method were appropriate, where the lowest stability coefficient was $(0.81)$ for the sense of safety, while the highest stability coefficients was (0.86) for sense of belonging). The lowest stability coefficients for mid-range split method was ( 0 . 79 ) for sense of goal, while the highest stability coefficient was $(0.85)$ for the sense of belonging. All these values are suitable for study and research purposes.

2) Measure of Exposure to Abuse:

The measure was designed in that it consists of 5 possible alternative responses for each item as in Likert scale. The levels $(5,4,3,2,1)$ reflect the degree of applicability of the student's abuse extent (very large, large, Medium, low, very low) respectively, so that the items are divided into dimensions of physical, psycho-emotional-emotional, and negligence abuse.

Validity of Abuse Measure:

1) Validity of Content:

The scale was submitted to (7) specialized reviewers, and a specialist in the field of language and grammar, to show the structure of the items in terms of language accuracy and clarity of meaning, and to indicate the extent of adherence of the items to the dimension in which it was placed, The items agreed upon by the reviewers exceeded $80 \%$ or more, were adopted.

2) Validity of Structure:

The measure of exposure to abuse was applied to an external sample of 30 students. They were randomly selected. The validity of structure was calculated through the correlation coefficients values in the fields in which they were included, as shown in Table 4. 
Table 4. Correlation matrix between the dimensions of the measure of exposure to abuse

\begin{tabular}{lccc}
\hline Dimensions & Physical Abuse & Psycho-emotional Abuse & Negligence \\
\hline Physical Abuse & ----- & 0.06 & $0.22^{* *}$ \\
Psycho-emotional Abuse & 0.18 & ----- & $0.42^{* *}$ \\
Negligence & 0.05 & $0.35^{* *}$ & ---- \\
\hline
\end{tabular}

**: all correlations are significant at $\alpha<0.05$.

Table 4 show that Pearson correlation coefficients between the dimensions of the test are statistically significant at $(\alpha<0.05)$

Stability of the Measure of Exposure to Abuse:

The stability of the scale was confirmed in two ways: the first was made by using the Cronbach Alpha equation, while the second was made by the mid-range split stability of each dimension of the scale separately, and for the total number of items after applying it to the explorative survey sample. Table 5 shows stability coefficients according to the Cronbach Alpha equation and the mid-range split of the various dimensions of the scale.

Table 5. The values of stability coefficients according to the Cronbach Alpha equation and the mid-range split of the various dimensions of the measure of exposure to abuse

\begin{tabular}{lcc}
\hline \multirow{2}{*}{ Dimension } & Stability Coefficient by Cronbach-Alpha & Stability Coefficient by mid-range split \\
\cline { 2 - 3 } & Sample N=30 & Sample N=30 \\
\hline Physical Abuse & 0.85 & 0.88 \\
Psycho-emotional Abuse & 0.84 & 0.86 \\
Negligence & 0.80 & 0.82 \\
\hline
\end{tabular}

The table indicates that the stability coefficients in the Cronbach Alpha method were appropriate where the lowest stability coefficients was $(0.80)$ for negligence, while the highest stability coefficients was $(0.85)$ for physical abuse. The Stability coefficients by using mid-range split was $(0.82)$ for negligence, while the highest stability coefficients was 0.88 for physical abuse. All these values fit the study and research purposes.

\subsection{Statistical Processing}

In order to answer the study questions, the data was collected, entered and calculated by using the SPSS statistical package, which included the measures of central tendency, correlation coefficients, statistical significance measures, and ANOVA variance analysis.

\section{Results and Discussion of the Study}

1) The results related to the first question:

Are there statistically significant differences in the reduction of the effects of abuse due to the play-based training program between the experimental group and the control group?

ANOVA analysis was conducted to identify the effectiveness of the training program, play therapy to reduce the negative effects of abuse on students on the scale of exposure to abuse, and its three dimensions as shown in Table 6.

Table 6. The statistical means and standard deviations of the responses of students on the scale of exposure to abuse and its three dimensions depending on the variable of the training program

\begin{tabular}{lcccc}
\hline \multirow{2}{*}{ Dimensions } & \multicolumn{3}{c}{ Group } \\
\cline { 2 - 5 } & \multicolumn{2}{c}{ Experimental Group } & \multicolumn{2}{c}{$\begin{array}{c}\text { Control Group } \\
\mathrm{N}=30\end{array}$} \\
\cline { 2 - 5 } & Mean & Standard Deviation & Mean & Standard Deviation \\
\hline Physical Abuse & 29.22 & 3.20 & 38.60 & 4.67 \\
Psycho-emotional Abuse & 31.28 & 3.60 & 39.20 & 3.82 \\
Negligence & 30.00 & 3.99 & 36.88 & 4.64 \\
\hline
\end{tabular}


Table 6 shows that there are some differences between the mean responses of students who were on the abuse scale and their three dimensions according to the training course. The mean response of students in the experimental group for physical abuse was 29.22, compared to 38.60 in the control group.

As shown in the table, there were some differences in the psycho-emotional abuse, where the mean response of students in the experimental group was 31.28, compared to 39.20 in the control group There were some differences in negligence, where the mean response of students in the experimental group was (30.00), compared to 36.88 in the control group. Table 7 shows the significance of examining the differences between the responses of abused students according to the training course.

Table 7. Results of multivariate variance analysis of students' response on the abuse scale according to the variable of the training program

\begin{tabular}{lccccc}
\hline Variable & Source & Freedom Deg & Mean & F value & Significance \\
\hline \multirow{3}{*}{ Physical Abuse } & Between groups & 1 & 1484.62 & & \\
& Intra Groups & 58 & 236.16 & 3.08 & 0.001 \\
& Total & 59 & -- & & \\
Psycho-emotional Abuse & Between groups & 1 & 1093.94 & & \\
& Intra Groups & 58 & 105.12 & \multirow{2}{*}{31.2} & 0.00 \\
& Total & 59 & -- & & \\
Negligence Abuse & Between groups & 1 & 9660.22 & & \multirow{2}{*}{0.005} \\
& Intra Groups & 58 & 330.16 & 468.4 & \\
\hline
\end{tabular}

Table 7 indicates that there is a statistically significant impact at the level of significance $(\alpha \leq 0.05)$ for the variable of the training program on the physical abuse, where the value of "F", resulting from the analysis of the single variance, was (3.08) with a probability of (0.001). This indicates that there is a statistically significant difference, at the level of $(\alpha \leq 0.05)$, between the mean performance of the experimental group and the control group, on the measure of exposure to abuse for the physical abuse. In regard to these means in Table 6 , there is a difference in favor of the performance of the experimental group members.

The results also show that there is a statistically significant impact at the level of significance $(\alpha \leq 0.05)$ for the variable of the training program on the psycho-emotional abuse, where the value of "F", resulting from the analysis of the single variance, was 31.2 while this value is related to the probability of $(0.00)$. This indicates that there is a statistically significant difference at the level of $(\alpha \leq 0.05)$ significance, between the mean performance of the experimental group and the control group on the measure of exposure to psycho-emotional abuse. Given these means in Table 6, this difference is in favor of the performance of the experimental group members.

The results also show that there is a statistically significant impact, at the level of significance $(\alpha \leq 0.05)$, for the variable of the training program on negligence, where the value of " $F$ ", resulting from the analysis of the single variance, was 468.), and the 0.005 . This indicates that there is a statistically significant difference at the level of significance $(\alpha \leq 0.05)$ between the average performance of the experimental and control group, on the scale of negligence. Given these averages in Table 6 , this difference is in the favor of the members of the experimental group.

The reasons for these results may be attributed to the strategies of the training program. The treatment of the play applied in this study, which helps to increase the self-control of the trainee, express senses in a proper manner, communicate with others and work to build good relations with them that have a positive impact on raising self-esteem among the experimental group.

This result may be due to the nature of the training program implemented in this study, which affected all trainees (male and female) positively, resulting in a reduction in the negative effects of abuse.

2) Results related to the second question:

Are there statistically significant differences in the level of self-esteem due to the play-based training program between the experimental group and the control group?

In order to identify the effectiveness of the training program, play therapy was used to improve the level of self-esteem of the abused students on the self-assessment scale and its five dimensions as shown in Table 8 . 
Table 8. The statistical means and standard deviations of the responses of abused students on the scale of exposure and its three dimensions according to the variable of the training program

\begin{tabular}{lcccc}
\hline \multirow{2}{*}{ Dimensions } & \multicolumn{3}{c}{ Group } \\
\cline { 2 - 5 } & \multicolumn{2}{c}{ Experimental Group } & \multicolumn{2}{c}{ Control Group } \\
$\mathrm{N}=30$
\end{tabular}

Table 8 shows the mean responses of the students on the self-assessment scale and its five dimensions, according to the training course. The mean response of the students in the experimental group for sense of safety was 40.21 , compared to 34.88 in the control group.

The mean response of abused children in the experimental group for sense of self-identity was 38.65 , compared to 32.96 in the control group.

The mean response of abused students for sense of belonging in the experimental group was 40.08, compared to 35.14 in the control group.

The mean response of students for sense of goal was 40.15 in the experimental group compared to 36.10 in the control group were.

Finally, the mean response of the abused students for sense competent in the experimental group was 37.60, compared to 31.22 in the control group.

Table 9 shows the implications of examining the differences between the responses of abused students who participated in the training program of play therapy.

Table 9. Results of multivariate variance analysis of students' responses to the self-assessment scale according to the variable of the training program

\begin{tabular}{lccccc}
\hline Variable & Source & Freedom Deg & Mean & F value & Significance \\
\hline \multirow{4}{*}{ Sense of safety } & Between groups & 1 & 2668.12 & & \\
& Intra Groups & 58 & 236.16 & 29.22 & 0.000 \\
& Total & 59 & -- & & \\
Between groups & 1 & 2782.18 & & \\
& Intra Groups & 58 & 241.16 & \multirow{2}{*}{3.04} & 0.00 \\
& Total & 59 & -- & & \\
Sense of belonging & Between groups & 1 & 4260.46 & & \multirow{5}{*}{ Intra Groups } \\
\cline { 2 - 4 } Sense of goal & Total & 58 & 240.22 & 31.3 & 0.001 \\
& Between groups & 1 & -2562.46 & & \\
& Intra Groups & 58 & 610.28 & 39.64 & 000 \\
Sense of efficacy & Total & 59 & -- & & \\
& Between groups & 1 & 4612.8 & & \\
& Intra Groups & 58 & 122.22 & 8.49 & 0.005 \\
\hline
\end{tabular}

Table 9 indicates that there is a statistically significant effect, at the level of significance $(\alpha \leq 0.05)$, for the variable of the training program on sense of safety. The value of "F", resulting from the analysis of the variance, was 29.22 with a probability of 0.000 .

This indicates that there is a statistically significant difference, at the level of significance $(\alpha \leq 0.05)$, between the mean performance of the experimental group and the control group, for the self-assessment scale on the sense of safety. In regard to these means of Table8, this difference is in favor of the performance of the experimental group members. 
The results show that there is a statistically significant effect at the level of significance $(\alpha \leq 0.05)$ for the variable of the training program on the sense of self-identity, where the value of "F", resulting from the analysis of the single variance, was 3.04 related to a probability of 0.000 .

This indicates that there is a statistically significant difference at the level of significance $(\alpha \leq 0.05)$ between the mean performance of the experimental group and the control group. Given these means in Table 8 , this difference is in favor of the performance of the experimental group.

Table 9 indicates that there is a statistically significant effect, at the level of significance $(\alpha \leq 0.05)$, for the variable of the training program, on the sense of belonging. The value of " $\mathrm{F"}$ ", resulting from the analysis of the single variance, was 31.3 at a probability degree of 0.001 .

This indicates that there are statistically significant differences, at the level of significance $(\alpha \leq 0.05)$, between the mean performance of the experimental group and the control group, on the self-esteem scale for the sense of belonging. In view of these means in Table 8, we note that this difference was in favor of members of the experimental group.

The results also show that there is a statistically significant effect, at the level of significance $(\alpha \leq 0.05)$,for the variable of the training program on the sense of the goal, where the value of " $F$ ", resulting from the analysis of the single variance, was 8.49 that related to a probability degree of 0.000 . This indicates that there are statistically significant differences at the mean level $(\alpha \leq 0.05)$ between the mean performance of the experimental group and the control group in favor of the experimental group.

The results also show that there is a statistically significant effect, at the level of significance $(\alpha \leq 0.05)$, for the variable of the training program on the sense of competency, where the value of "F", resulting from the analysis of the single variance, was 8.49 which related to probability degree of 0.005 .

This indicates that there are statistically significant differences at the significance level $(\alpha \leq 0.05)$ between the mean performance of the experimental group and the control group for the favor of the experimental group.

The result may also be due to the positive atmosphere that prevailed among the children participating in the affirmative training program, which has a positive effect on the formation of friendships, the exchange of experiences, the sharing of concerns, the identification of individuals with the same characteristics, traits and the same problems.

This outcome may be due to the characteristics and benefits of the treatment of the play therapy, upon which the training program was adopted, which is one of the methods used to treat children who experience emotional difficulties or trauma as a result of being abused.

The treatment method is an effective method of psycho-emotional therapy for abused children, according to Bryce (1995), Gill (1997) and Utah (1998), all of which concluded that there was a statistically significant effect in favor of treatment therapy programs in raising the level of self-esteem.

3) Results related to the third question:

Are there statistically significant differences in the effects of abuse among the experimental and control group due to Gender?

Means and standard deviations were applied, as well as using the ANOVA to identify the effect of gender on reducing the negative effects of abuse against students on the scale of abuse and its three dimensions as shown in Table 10 .

Table 10. The arithmetical means and standard for the responses of students on the abuse scale, and its three dimensions depending on the variable of the training program

\begin{tabular}{lcccc}
\hline \multirow{2}{*}{ Dimensions } & \multicolumn{3}{c}{ Group } \\
\cline { 2 - 5 } & \multicolumn{3}{c}{ Male Group } & \multicolumn{2}{c}{ Female Group } \\
& $\mathrm{N}=30$ & & $\mathrm{~N}=30$ \\
\cline { 2 - 5 } & Mean & Standard Deviation & Mean & Standard Deviation \\
\hline Physical Abuse & 34.86 & 3.90 & 35.66 & 4.00 \\
Psycho-emotional Abuse & 33.44 & 3.60 & 32.79 & 3.77 \\
Negligence & 35.00 & 4.22 & 34.92 & 4.12 \\
\hline
\end{tabular}

Table 10 shows that there were some differences between the mean responses of the abused students who applied 
the abatement scale and the three dimensions depending on the gender variable. The mean response of male abused students was 34.86 for the physical abuse compared to 35.66 for female students. The mean response of male students to emotional abuse was 33.44 , compared to 32.79 for female students. The mean response of male respondents was 35.00 , compared to 34.92 for female students. Table 11 shows the significance of examining the differences between the responses of abused according to the gender variable.

Table 11. The results of multivariate variance analysis of the responses of students on the scale of exposure to abuse according to gender

\begin{tabular}{lccccc}
\hline Variable & Source & Freedom Deg & Mean & F value & Significance \\
\hline \multirow{2}{*}{ Physical Abuse } & Between groups & 1 & 462.12 & & \\
& Intra Groups & 58 & 68.08 & 18.18 & 0.24 \\
& Total & 59 & -- & & \\
Psycho-Emotional Abuse & Intra Groups & 58 & 246.44 & 11.87 & 0.38 \\
& Total & 59 & -- & & \\
& Between groups & 1 & 2263.04 & & \\
& Intra Groups & 58 & 68.82 & 21.66 & 0.42 \\
Negligence abuse & Total & 59 & -- & & \\
\hline
\end{tabular}

Table 11 indicates that there is no statistically significant effect, at the level of $(\alpha \leq 0.5)$, of the gender variable on all dimensions of the scale. The value of " $F$ ", resulting from the analysis of the unilateral variance, was 18.18 , which is associated with a probability of 0.24 . The value of " $F$ ", resulting from the analysis of the unilateral variance, was 31.2 , for psycho-emotional abuse, where this value is associated with a probability equal to 0.38 . The value of " $F$ " was 21.66 , for negligence abuse and this value are associated with a probability equal to 0.42 .

These results indicate that there is no statistically significant difference at the level of significance $(\alpha \leq 0.5)$ between the means of male and female performance on exposure to abuse scale. This result may be due to developmental characteristics that distinguish the abused children from others regardless the gender of the child, which may be a reason for abuse.

The result may also be due to parental risk factors, where the children involved in the training share one environment and similar families. Maltin (2001) found that parental characteristics are the drives for child abuse, and that lack of knowledge, skills and parental skills lead to abuse and negligence of these children regardless their gender. The results of this study were consistent with the results of (Kim, 2005)

\section{Recommendations}

In the light of the findings of the present study, recommendations could be as follows:

1) Pay attention to the protection and care of children, through providing parents and teachers with information about the upbringing and care of children and their needs, without violence.

2) Conduct training programs (workshops) to help both children's teachers and parents to provide them with approaches to raise their self-esteem.

3) Early intervention in the protection of children from the abuse they are subjected to, and collaborate to stop abusing them by counseling and directing everyone deals with children, and training children to protect themselves from abuse.

4) Conduct further studies on the protection of children from abuse, to increase the awareness of children caring for children of the dangers of child abuse, which will continue to affect them for lifelong, and the consequent development of aggression against the family and society.

\section{References}

Abdul Jawad, W., \& Khalil, A. (1999). Effectiveness of a program to reduce aggressive behavior using playing of children with hearing disabilities. Journal of Psychology, 50.

Abu Aliya, M. (2000). Family violence: types, forms and causes, seminar (to work together for a happy family free of violence). Zarqa: Hashemite University, Family Awareness and Guidance Center.

Al-Safi, A. H., \& Dabur, A. L. (2007). School Counseling between theory and practice. Amman: Dar Al Fikr for Publishing and Distribution 
Al-Safi, A. H., \& Qara, S. (2009). The art of dealing with people. Amman: Addustour for Publishing and Distribution.

Annunziata, J. (2003). Play Therapy with A6-Year Old. American Psychological Association.

Asala, S. K. (2004). Forms of parental abuse of the child and their relation to the level of parental education, family income and aggressive behavior of children (Unpublished master thesis). University of Jordan.

Bryce, A. (2005). An Intervention Design and Out Come Study of an Expressive Therapy Group for Sexually Abused School Age Girls (Phd dissertation, Antioch University New England Graduate School). Abstracts International.

Chalabi, S. S. (2003). The impact of violence and child abuse on the future personality. Arab Psycho-emotional Network.

Chen, X., Liu, M., \& Li, D. (2000). Parental Warmth, Control, and Indulgence and Their Relations to Adjustment in Chinese Children: A longitudinal Study. Journal of Family Psychology, 14(3), 401-419. https://doi.org/10.1037//0893-3200.14.3.401

Darwish, D., Esquivel, B., Houtz, C., \& Alfonso, S. (2002). Play and Social Skills in Maltreated and Non Maltreated Preschoolers During Peer Interactions. Child Abuse \& Neglect, 5(1), 13-31. https://doi.org/10.1016/s0145-2134(00)00228-3

Decker, C. A. (1995). Children: The Early Years. Goodheart-Willcox Co. South Holland, IL, USA.

Gill, R. (2005). Post-Traumatic Stress Disorder in latency Age Child: Psychodynamic Treatment Approach. Dissertation Abstracts International, 80(57), 5325.

Hatter, J. (1995). The Impact of therapeutic Drama on Self-Esteem (Unpublished master thesis). University of Jordan. the Hashemite Kingdom of Jordan.

Ibrahim, A. (1994). Use of psychodrama to reduce emotional disorders in children (Unpublished PhD thesis). Ain Shams University.

Lussier, P., \& Leblanc, M. (2005). Criminal Propensity, Deviant Sexual Interests and Criminal Activity of Sexual Aggressors Against Women: Comparison of Explanatory Models. Criminology, 43(1), 249-281. https://doi.org/10.1111/j.0011-1348.2005.00008.x

Matlin, W. (2001). Psychology of Women (4th ed., pp. 262-284). Harcourt College Publishers.

Muro, J., \& Kottman, T. (1995). Guidance and Counseling in the Elementary and Middle School. Brown and Benchmark Publishers.

Ratrout, S. A. (2000). Child mental retardation as one of the risk factors driving abuse. Arab Network for People with Special Needs.

Report of the Secretary-General of the United Nations. (2006). In-depth study on all forms of violence against women.

Shen, Y., \& Sink, C. S. (2002). Helping Elementary Age Children Cope with Disasters. Professional School Counseling, 5(5), 322-330. Retrieved from https://www.jstor.org/stable/42732372

Taha, A. A. (2008). Child Abuse: Theory and Therapy. Amman: Dar Al Fikr for Publishing and Distribution.

Vig, S., \& Kaminer, R. (2002). Maltreatment and developmental disabilities in children. Journal of Developmental and Physical Disabilities, 14(4), 371-386. https://doi.org/10.1023/A:1020334903216

Woolfolk, A. E. (2006). Educational Psychology (7th ed.). Boston, Allyn \& Bacon.

Zahran, H. (2001). Psychology of Childhood and Adolescent Growth (5th ed.). Cairo, Egypt, World of Books.

\section{Copyrights}

Copyright for this article is retained by the author(s), with first publication rights granted to the journal.

This is an open-access article distributed under the terms and conditions of the Creative Commons Attribution license (http://creativecommons.org/licenses/by/4.0/). 